\title{
APLIKASI Dolichoderus sp. UNTUK PENGENDALIAN Helopeltis spp. PADA TANAMAN KAKAO
}

\author{
Andi Ridwan ${ }^{1)}$ Ahdin Gassa ${ }^{2)}$ Tamrin Abdullah ${ }^{2)}$ \\ 1) Jurusan Budidaya Tanaman Perkebunan, Politeknik Pertanian Negeri Pangkep \\ Jl. Poros Makassar Pare-Pare Km. 86 Kecamatan Mandalle Kabupaten Pangkep \\ ${ }^{2)}$ Departemen Hama dan Penyakit Tumbuhan, Fakultas Pertanian Universitas Hasanuddin \\ Jl. Perintis Kemerdekaan Km. 10 Makassar \\ Korespondensi: ridwanassaad@gmail.com
}

\begin{abstract}
ABSTRAK
Penelitian yang bertujuan untuk meningkatkan peranan Dolichoderus sp dalam mengendalikan Helopeltis spp telah dilaksanakan di kebun kakao milik rakyat. Kegiatan yaitu memasang sebanyak dua sarang buatan masing-masing pada dua sisi yang berlawanan pada cabang kakao. Hasil pengamatan menunjukkan bahwa tanaman kakao setelah tiga bulan pemasangan sarang buatan tingkat serangan Helopeltis spp mengalami penurunan yaitu menjadi 8,86\% dari semula sebelum pemasangan sarang buatan tingkat serangan Helopeltis yaitu 46,6\%. Sarang buatan sangat membantu dalam meningkatkan populasi Dolichoderus sp. yang dikenal sebagai predator atau musuh alami Helopeltis spp. pada tanaman kakao.
\end{abstract}

Kata kunci: Dolichoderus sp , Helopeltis spp. Predator, dan sarang buatan

\begin{abstract}
Research which aim to improve the Dolichoderus sp function in controlled Helopeltis spp which has been implemented in public cocoa garden. The activity is set two artificial nest each at two contrast side on cocoa branch. Result of study is show that cocoa tree after three months of the artificial nest installation the level of Helopeltis spp attack is run in to lower is being $8,86 \%$ by first time before artificial nest installation the level of Helopeltis attack is $46,6 \%$. The artificial nest is very help to increase the Dolichoderus sp population. Which knowing as the predator or Helopeltis spp natural enemy on cocoa tree.
\end{abstract}

Keywords: Dolichoderus sp, Helopeltis spp. Predator, and artificial nest.

\section{PENDAHULUAN}

Tanaman kakao tergolong komoditi perkebunan yang memiliki nilai ekonomis yang cukup tinggi dan relatif stabil. Tanaman kakao sangat potensial dan diminati oleh petani karena selain harganya yang relatif tinggi juga proses panen komoditi ini bisa dilakukan setiap minggu. Sebagai salah satu komoditi unggulan ekspor Indonesia, Kakao tetap berpotensi menjadi produk unggulan pertanian di Indonesia karena iklim tropis Indonesia yang sangat mendukung sehingga syarat tumbuh tanaman tersebut dapat terpenuhi. Hingga saat ini, Indonesia merupakan produsen kakao nomor tiga terbesar di dunia setelah Pantai Gading dan Ghana. 
Data tahun 2019 menunjukkan bahwa pantai Gading menghasilkan 2.000.000 ton, Ghana menghasilkan 880.000 ton, dan Indonesia menghasilkan 260.000 ton biji kakao kering (Kemenperin, 2019)

Organisme pengganggu tanaman (OPT) merupakan faktor kendala dalam budidaya kakao. Salah satunya adalah Helopeltis spp. Hama ini merupakan hama utama yang biasanya menyerang buah kakao yang masih muda dengan cara menusuk dan menghisap cairannya sehingga buah berkembang tidak normal (Utami et al., 2017). Di Indonesia, jenis Helopeltis yang menyerang tanaman kakao adalah Helopeltis bradyi ( Melina et al., 2016), serta Helopeltis antonii dan Helopeltis theivora (Kalshoven, 1991). Serangan Helopeltis ini menurunkan kualitas hasil produksi kakao hingga 80 \% (Ditjenbun, 2006; Wiryadiputra, 2007). Untuk mengendalikan hama tersebut, sering dengan penggunaan bahan kimiawi. Efek residu dalam biji kakao, pencemaran lingkungan dan terbunuhnya organisme lain yang bukan sasaran adalah efek negatif dari pengendalian OPT dengan aplikasi pestisida kimia. Sementara dalam praktisnya, pengendalian dengan pestisida kimia adalah alternatif terakhir dalam menekan OPT dalian dapat dilakukan untuk menekan perkembangan Helopeltis spp tapi perlu diperhitungkan dampak yang ditimbulkannya. Pengendalian hama secara kimia menggunakan insektisida dianggap ampuh untuk menekan perkembangan Helopeltis spp tetapi menimbulkan efek negatif terhadap mikroorganisme lainnya yang mungkin bermanfaat bagi tanaman kakao. Oleh karena itu diperlukan adanya suatu teknik pengendalian yang dapat menekan perkembangan hama serta dampak negatif yang ditimbulkan dari proses pengendalian tersebut (Roy et al., 2011)

Dolichoderus sp. terbukti efektif sebagai pengendali Penggerek buah kakao (Acrocercop cramerella) pada tanaman kakao dan begitu juga untuk Helopeltis spp.(Gassa dan Rahmat, 2009). Meskipun demikian di lapangan terkadang Dolichoderus sering tidak berfungsi secara optimal dikarenakan populasinya yang rendah. Oleh karena itu diperlukan adanya upaya Untuk meningkatkan populasi sehingga peranan Dolichoderus sp sebagai pengendali Helopeltis spp. pada tanaman kakao dapat lebih optimal.

\section{BAHAN DAN METODE}

Kegiatan dilaksanakan pada lahan kakao yang sedang berbuah milik petani yang dipastikan tidak menggunakan insektisida. Adapun hal-hal yang dilakukan adalah:

1. Menentukan 3 kelompok buah kakao sebagai objek pengamatan pada lahan dimana setiap kelompok buah terdiri atas 5 pohon kakao yang berdekatan dan sedang berbuah lebat. 
2. Melakukan pengamatan awal terhadap intensitas serangan Helopeltis sp pada buah kakao pada saat panen.

3. Memasang sarang buatan untuk koloni semut Dolichoderus sp. pada tanaman kakao. Sarang dibuat dari bahan daun kelapa kering yang dimasukkan kedalam potongan bambu ukuran panjang $\pm 30 \mathrm{~cm}$ lalu ditempatkan pada ranting-ranting tanaman kakao. Sarang dipasang hanya pada tanaman kakao yang terdapat pada kelompok buah. Setiap pohon kakao pada masing- masing kelompok buah diberi dua sarang buatan pada cabang atau ranting dengan arah berlawanan dan diusahakan terlindung dari cahaya matahari langsung. Untuk menarik kehadiran semut,sarang buatan diberi larutan gula.

4. Setelah tiga bulan pemasangan sarang, dilakukan pengamatan intensitas serangan Helopeltis sp Jumlah buah sampel yang diamati pada setiap kelompok buah adalah minimal 100 buah. Intensitas serangan Helopeltis dihitung menggunakan rumus yang digunakan oleh Sulistyowati (2008),

$$
\begin{array}{rll}
\mathrm{I}=(\mathrm{R}+3 \mathrm{~S}+9 \mathrm{~B}) / 9 \times \mathrm{A}: \\
\mathrm{I} & = & \text { intensitas serangan, } \\
\mathrm{R} & = & \text { serangan ringan, } \\
\mathrm{S} & = & \text { serangan sedang, } \\
\mathrm{B} & = & \text { serangan Berat, } \\
\mathrm{A} & = & \text { Jumlah buah yang di amati. }
\end{array}
$$

Buah yang dipanen dikelompokkan dalam 3 kategori serangan yaitu : 0. (Tidak ada serangan) 1.Ringan (bercak buah $<25 \%$ ), 2. ( Sedang (bercak 25-50\%), 3. (Berat (bercak $>50 \%$ ).

\section{HASIL DAN PEMBAHASAN}

Hasil pengamatan awal secara acak terhadap tingkat serangan Helopeltis di pertanaman kakao cukup bervariasi dari kategori ringan, sedang hingga berat. Tingkat serangan Helopeltis spp pada tanaman kakao dapat di lihat pada Tabel 1:

Tingkat serangan Helopeltis pada buah kakao yang diamati pada tiga lokasi sebelum pemasangan sarang bervariasi yaitu dari 35, 48, dan 55 persen dengan rata-rata persentase tingkat serangan adalah 46,6\%. Hasil pengamatan pada tabel 1 terhadap Jumlah buah yang tidak terserang rata-ratanya adalah sebesar 5 buah. Pengamatan setelah tiga bulan pemasangan sarang buatan menunjukkan tingkat serangan Helopeltis cenderung lebih rendah. Hasil pengamatan tersebut ditunjukkan pada Tabel 2. 
Tabel 1. Tingkat Serangan Helopeltis spp pada Tanaman Kakao yang diamati Sebelum Pemasangan Sarang buatan.

\begin{tabular}{ccccccc}
\hline $\begin{array}{c}\text { Kelompok } \\
\text { Buah }\end{array}$ & $\begin{array}{c}\text { Jumlah } \\
\text { buah } \\
\text { yang di } \\
\text { amati }\end{array}$ & $\begin{array}{c}\text { Jumlah } \\
\text { buah } \\
\text { yang } \\
\text { tidak } \\
\text { terserang }\end{array}$ & $\begin{array}{c}\text { Jumlah } \\
\text { Buah } \\
\text { yang } \\
\text { terserang } \\
\text { ringan }\end{array}$ & $\begin{array}{c}\text { Jumlah } \\
\text { Buah } \\
\text { yang } \\
\text { terserang } \\
\text { sedang }\end{array}$ & $\begin{array}{c}\text { Jumlah } \\
\text { Buah } \\
\text { yang } \\
\text { terserang } \\
\text { berat }\end{array}$ & $\begin{array}{c}\text { Tingkat } \\
\text { serangan }\end{array}$ \\
\hline I & 100 & 5 & 42 & 33 & 20 & 35,6 \\
II & 100 & 7 & 13 & 50 & 30 & 48,1 \\
III & 100 & 3 & 17 & 40 & 40 & 55,2 \\
\hline Rata-rata & & & & & 46,6 \\
\hline
\end{tabular}

Tabel 2. Tingkat Serangan Helopeltis spp pada Tanaman Kakao Setelah Tiga Bulan Pemasangan Sarang buatan

\begin{tabular}{ccccccc}
\hline $\begin{array}{c}\text { Kelompok } \\
\text { Buah }\end{array}$ & $\begin{array}{c}\text { Jumlah } \\
\text { Buah } \\
\text { Yang } \\
\text { diamati }\end{array}$ & $\begin{array}{c}\text { Jumlah } \\
\text { buah } \\
\text { yang } \\
\text { tidak } \\
\text { terserang }\end{array}$ & $\begin{array}{c}\text { Jumlah } \\
\text { buah } \\
\text { terserang } \\
\text { Ringan }\end{array}$ & $\begin{array}{c}\text { Jumlah } \\
\text { Buah } \\
\text { Terserang } \\
\text { Sedang }\end{array}$ & $\begin{array}{c}\text { Jumlah } \\
\text { Buah } \\
\text { Terserang } \\
\text { Berat }\end{array}$ & $\begin{array}{c}\text { Tingkat } \\
\text { Serangan } \\
(\%)\end{array}$ \\
\hline I & 100 & 40 & 50 & 7 & 3 & 10,8 \\
II & 100 & 55 & 39 & 3 & 3 & 8,3 \\
III & 100 & 60 & 29 & 10 & 1 & 7,5 \\
\hline
\end{tabular}

Berdasarkan persentase serangan pada tabel 2 terlihat bahwa tingkat serangan Helopeltis spp pada tanaman kakao setelah dibuat sarang buatan menjadi lebih rendah dengan tingkat serangan bervariasi dari 10,8 persen, 8,3 persen, dan 7,5 persen dengan ratarata tingkat serangan sebesar 8,8 persen. Adapun jumlah buah yang tidak terserang rata-rata adalah 51 buah.

Tingkat serangan Helopeltis spp yang bervariasi berkaitan dengan keberadaan populasi Dolichoderus sp pada tanaman kakao. Hasil pemantauan menunjukkan bahwa pada pohon - pohon kakao dengan populasi semut yang agak tinggi serangan hama kepik Helopeltis rendah. Dan sebaliknya pada pohon sampel dimana keberadaan semut agak kurang terlihat bahwa tingkat serangan helopeltis tinggi. Semut berfungsi secara tidak langsung melindungi secara fisik buah kakao dari serangan penghisap buah hama kepik Helopeltis. Populasi semut dikategorikan tinggi bila disepanjang batang atau cabang, dan juga 
buah ditemukan keberadaannya (Ho and Khoo, 1997). Semut berkeliaran di pertanaman kakao untuk mencari makan dan tempat berlindung. Aktivitas semut tersebut menyebabkan hama kepik Helopeltis terganggu dan terusir dari tanaman kakao dan tidak sempat merusak dan melakukan perkembangbiakan pada tanaman kakao (Puslitkoka, 2010)

Hasil pengamatan tingkat serangan Helopeltis spp pada tanaman kakao jika dibandingkan pada kedua tabel di atas menunjukkan bahwa, terjadi penurunan yang cukup tinggi yaitu dari 46,6\% sebelum diberi sarang buatan menjadi 8,86 tingkat serangannya setelah diberi sarang buatan. Demikikian juga jumlah buah yang tidak terserang rata-rata 5 buah pada table 1 dan pada table 2 , jumlah buah yang tidak terserang rata-ratanya meningkat menjadi 51,6 buah. Hal ini membuktikan bahwa kehadiran semut dengan populasi tinggi membantu didalam mengurangi serangan Helopeltis spp pada tanaman kakao. Dalam Ditjenbung, 2006 diungkapkan bahwa pemberian sarang buatan akan cepat meningkatkan populasi Dolichoderus sp pada tanaman kakao.

Di perkebunan kakao populasi Dolichoderus terlihat berkembang dengan baik. Hal ini disebabkan adanya pemberian sarang buatan dan juga di lahan tidak digunakan pestisida (insektisida). Insektisida merupakan senyawa yang bersifat racun dan dapat membunuh berbagai jenis serangga.

Stadia merusak Helopeltis spp adalah nimfa dan imago yaitu dengan cara menusuk dan menghisap cairan sel, akibatnya timbul bercak- bercak cekung berwarna coklat- kehitaman (Susanto, 1994). Dalam aktivitas makannya, cairan ludah yang mengandung racun dimasukkan ke dalam sel- sel tanaman, gejala awal yang muncul adalah mula- mula akan terlihat seperti adanya cairan disekitar tusukan. Cairan tersebut kemudian berubah warna menjadi coklat muda pada pusatnya dan hitam pada tepinya. Serangan Helopeltis pada buah muda dapat menimbulkan kematian, atau berkembang terus tetapi permukaan kulitnya menjadi retak dan bentuknya tidak normal, sehingga menghambat pembentukan biji. Serangan berat pada ranting dan pucuk menyebabkan layu dan mati (Sulistyowati, 2006)

Potensi semut hitam (Dolichoderus sp). merupakan salah satu musuh alami yang dapat digunakan untuk mengendalikan hama (Helopeltis sp). Jenis Dolichoderus sp ini merupakan bagian dari agroekosistem perkebunan kakao (Ho \& Khoo, 1997). Dolichoderus akan berfungsi sebagai agen pengendali hayati jika populasinya di ekosistem kakao melimpah. 
Pemanfaatan Dolichoderus sp sebagai agen pengendali kepik Helopeltis sp. sudah dikenal sejak lama, namun kebanyakan petani masih jarang menerapkan cara pengendalian ini Helopeltis spp. Biasanya aktif melakukan serangan pada pagi dan sore hari. Hama ini melakukan serangan dengan cara menusukkan stilet pada buah atau daun muda, hama ini juga meletakkan telur- telurnya pada permukaan buah, serta cabang pada tanaman kakao

Kehadiran Dolichoderus sp pada tanaman kakao menyebabkan Helopetis spp. terganggu dan terhalang untuk menusukkan stiletnya serta meletakkan telur pada permukaan buah atau pada bagian lain tanaman kakao. Ini menyebabkan tanaman kakao terhindar dari serangan Helopeltis spp (Graham, 1991). Demikian juga telurtelur Helopeltis yang ada dipermukaan buah atau cabang dan ranting akan dipredasi oleh Dolichoderus. Dan ini akan memutus siklus hidup helopeltis spp (Way and Khoo, 1992). Kondisi ini jika berlangsung terus- menerus maka dipastikan populasi Helopeltis spp. akan berkurang. Pengendalian Helopeltis spp menggunakan Dolichoderus sp pada tanaman kakao akan menguntungkan karena selain biaya murah juga relatif mudah penerapannya.

\section{KESIMPULAN}

Peranan Dolichoderus sp dalam mengendalikan Helopeltis spp meningkat dengan meningkatnya populasi Dolichoderus pada tanaman kakao. Tanaman kakao setelah tiga bulan pemasangan sarang buatan tingkat serangan Helopeltis spp mengalami penurunan yaitu menjadi $8,86 \%$ dari semula sebelum pemasangan sarang buatan tingkat serangan Helopeltis yaitu 46,6 \%. Untuk meningkatkan populasi Dolichoderus sp pada tanaman kakao dapat dilakukan dengan membuat sarang buatan.

\section{UCAPAN TERIMA KASIH}

Disampaikan terima kasih dan penghargaan kepada Direktorat Jenderal Pendidikan Vokasi, Kementerian Pendidikan dan Kebudayaan (Kemendikbud) yang telah mendanai penelitian ini.

\section{DAFTAR PUSTAKA}

Ditjenbun, 2006. Pedoman Teknis Pengendalian Hama Penggerek Buah Kakao pada Tanaman Kakao. Direktorat Jenderal Perkebunan. Departemen Pertanian. Jakarta.

Graham MK. 1991. Biological control of Helopeltis sp. in mature cocoa by the black ant (Dolichoderus bituberculatus) and the cocoa mealybug (Planococcus lilacinus). The Planter 67:543-546. 
Gassa, A., Rahmat, J. 2009. Evaluasi kinerja dan pengembangan beberapa spesies semut yang berpotensi sebagai agens pengendali hayati terhadap PBK. Laporan Penelitian Stranas DIPA UNHAS.

Ho CT, Khoo KC. 1994. Some factors influencing sustenance of high activity of black cocoa ant, Dolichoderus thoracicus (Hymenoptera: Formicidae) in cocoa estates. In: A Rajan \& YB Ibrahim (Eds.), Proceedings of the 4th International Plant Protection in the Tropics pp. 218-220. Kuala Lumpur: Malaysian Plant Protection.

Ho CT, Khoo KC. 1997. Partners in biological control of cocoa pests: mutualism between Dolichoderus thoracicus (Hymenoptera: Formid-idae and Cataenococcus hispidus (Hemiptera: Pseudococcidae). Bulletin of Entomological Research 87:461-470. http://dx.doi.org/10.1017/S0007485300041328.

Kalshoven LGE. 1981. The Pests of Crops in Indonesia.Laan PA van der, penerjemah. Jakarta (ID): Ichtiar Baru van Hoeve. Terjemahan dari: De Plagen van de Cultuurgewassen in Indonesie.

Kemenperin, 2019. Paket-Informasi-Komoditi-Kakao. http//kemenperin. go.id/download/290/Paket-Informasi-Komoditi-Kakao. Diakses 29 Juli 2019.

Melina, S., Trisyono, Y.Y., Martono, E. 2016. Confirmation That Helopeltis Species Attacking Cacao in Yogyakarta is Helopeltis Bradyi Waterhouse, Not Helopeltis Antonii Signoret (Heteroptera: Miridae). Jurnal Entomologi Indonesia. Vol. 13 No. 1, 9-20 Online version: http://jurnal.pei-pusat.org DOI: 10.5994/jei.13.1.9.

Puslitkoka, 2010. Semut Hitam untuk Pengendalian Hayati Hama Utama Tanaman Kakao. Pusat Penelitian Kopi dan Kakao. Indonesia, Jember.

Roy, S., Mukhopadhyay, A., \& Gurusubramanian, G. (2011). Resistance to insecticides in field-collected populations of tea mosquito bug (Helopeltis theivora Waterhouse) from the Dooars (North Bengal, India) tea cultivations. Journal of the Entomological Research Society, 13(2), 37-44.

Sulistyowati E (2008). Pengendalian hama kakao. Dalam: Wahyudi T, TR Pangabean \& Pujiyanto (Eds) Panduan Lengkap Kakao: Manajemen Agribisnis dari Hulu hingga Hilir. Jakarta, Penebar Swadaya

Untung, K. 2015. Pengantar Pengelolaan Hama Terpadu Edisi Ke 2. Cetakan Keenam. Penerbit: UGM Press. 348 hal.

Utami, A., Dadang, Nurmansyah, A. dan Laba, I.W.. 2017. Helopeltis antonii (Hemiptera: Miridae) Resistance Level In Cacao Plantation Against Three Types Of Synthetic Insecticide. Journal Tanaman Industri dan Penyegar. P-ISSN: 2356-1297

(2006). Pengenalan Hama Utama, Teknik Pengamatan dan Pengendaliannya pada tanaman Kakao. Materi Magang Dosen PPNP. Puslitkoka, Indonesia.

Wahyudi, T, dkk, 2011. Panduan Lengkap Kakao. Niaga Swadaya 
Way, M.J. \& Khoo, K.C. (1989). Relationships between Helopeltis theobromae damage and ants with special reference to Malaysian cocoa smallholdings. J. Pl. Prot. Tropics, 6, $1-11$.

Wiryadiputra, S. 2007. Establishment of Black Ant (Dolichoderus thoracicus) on Cocoa Plantation and Its Effects on Helopeltis spp. Infestation. Pelita Perkebunan 2007, 23(1), $57-71$ 